\title{
Intersectionality, British Criminology and Race: Are we there yet?
}

\begin{abstract}
Alpa Parmar ${ }^{1}$
Notwithstanding the well-established calls for race and ethnicity to be placed firmly on the criminological agenda (e.g. Bowling and Phillips, 2002), intersectional approaches in the UK have remained few and far between and accompanied by a lack of attention towards the actual processes of racialization inherent in the criminal justice system. The analytical power of adopting an intersectional lens and its capacity to expose how race, gender, class and generation interact and enmesh in the context of crime and punishment in the UK context was most recently demonstrated in an edited collection by Phillips and Webster (2013). However, beyond this, and aside from a few ethnographic studies (Bosworth 2014; Phillips 2012) race and racism are only arbitrarily discussed within mainstream British criminology and when they are, disproportionate outcomes are reiterated without further analysis about the reasons why. Overlapping concepts such as race, ethnicity and nationality remain unaddressed and there is a lag between the lived realities of minority ethnic groups and criminological academic scholarship. For example, despite the salience of religion in discourses about crime and terrorism, analyses about the intersection between racism, Islamophobia and criminalization are largely missing in mainstream criminological debate. Criminological questions remain stuck in a binary of trying to explain the overrepresentation of Black men in the criminal justice system through explanatory paradigms of discrimination or offending propensity (Bowling and Phillips 2012). In addition, analytically, exactly what is meant by racism tends to be taken for granted and criminology has arguably contributed to the hollowing out of the concept of racism (Miles 1989) and a culture of racial equivalence, whereby a multitude of disparate scenarios and interactions are referred to as 'racist' and thus deemed equivalent (Song 2014, 2016). Criminological studies that illuminate forms of resistance amongst racialized communities are scarce as are perspectives that interpret ethnic identity as a resource.
\end{abstract}

In the following essay, I will set out the parameters of intersectionality and discuss how and why it has had, so far, little effect on British criminology. As I will demonstrate, part of the problem in British scholarship has been an enduring reluctance to examine race. Drawing on my own research with the Asian community in the UK, I will demonstrate the complexity of race and ethnicity (and their convergence with gender, nationality, class and generation) and underscore their relevance for understanding the shifting nature of criminal justice control.

\footnotetext{
${ }^{1}$ I would like to thank Mary Bosworth, Kate West and Marion Vannier for their valuable comments on earlier drafts of this paper.
} 


\section{Intersectionality and British Criminology}

Intersectionality gained significant momentum through Crenshaw's application of Black feminist thought and critical race theory to critique the legal system and its privileging of some races over others (Potter 2015; Delgado and Stefancic 2012). Intersectionality refers to the conceptualization that each person has an assortment of coalesced socially constructed identities that are ordered into an inequitable social stratum (Potter 2015). The message of the approach is to enable multi-directional analysis - for example, to understand race through the lens of gender and to see gender through the lens of race. Class and other stratifying and exclusionary power structures are included in this framework as forms of oppression to be considered within the intersecting axes of race and gender. British legal scholars have demonstrated the need for intersectional analyses to be both understood and activated in UK courts, given the singledimension logic of equality law, and its impact on black women in the face of discrimination (Solanke 2009).

However, the application of an intersectional lens has remained marginal within British criminology and is less visible than was anticipated since its initial emergence in the social sciences in the 1980s. Despite the relevance of an intersectional perspective to most questions within criminology, its implementation has remained at the conceptual level (Potter 2015). British communities as sites of analysis often provide the most intricate entanglements of class, race/ethnicity, gender, and generation and so it has been particularly surprising to see a lack of engagement with all of these factors, and their consequences, when they intersect with criminalization. Although the concept of intersectionality has been advanced by feminist approaches and paradigms and approaches in the US (Renzetti et al 2006, Daly and Maher 1998) in the context of British criminology, paradoxically discussions about the workings and impacts of race have been obscured. Despite the capacity for intersectionality to bring together the parallel examination of race and ethnicity alongside other social cleavages, this has not been reflected in scholarship, and rather analyses tend to prioritise one social identity such as gender. Despite a considerable wealth of feminist inspired research on gender and crime and their attention to uncovering how gender intersects with race in the US (Maher 1999; Bosworth and Flavin 2007; Jones 2009; Richie 2012; Lamont 2010; Belknap 2015), the same cannot be said about British criminology, where race is rarely mentioned in feminist research.

Describing a struggle between race and gender may seem contradictory, given that the premise of intersectionality is to bring attention to the multiplicity of identities, including race. However, I suggest that the lack of critical attention to race, in British academia, has meant that intersectional criminological approaches in the UK have not sufficiently attended to race and its consequences. Significantly, intersectionality's reach was to be expansive rather than delimiting, and it is within this context that I 
write. In other words, I hope to inspire debate and thought about the place of race within the intersectional approach and British criminology.

The socio-political context for debates about race matters, and it is worth highlighting that intersectionality was originally conceived in the US (Crenshaw 1991; Collins 2000) and in a context where race was and is discussed widely and openly. The opposite is true in the UK. Here race is rarely discussed explicitly and despite cognate aspects between the US and UK (with regard to race and racism), the absence of agreed conceptual tools within the field of race and ethnicity studies is notable (Lentin 2016, Roth 2016). Specifically with regard to the UK, the lack of interrogation towards the joint formations of racism and nationalism (Gilroy, 1993; 2000) is particularly striking, given intersectionality's capacity to deftly accommodate such analyses. Reticence towards race in the British academy is often justified by claims that racism is waning and aberrant because we live in a post-racial society, which despite being vehemently contested (Goldberg 2016; Giroux 2009), is still given political credence through the lack of attention to policies to reduce racial inequality (Berkeley 2014). The reality is that in the lives of many people of colour, the criminal justice system is expanding, commonplace and located in system wide policies - beyond individual instances of racism and notions of intent (Murakawa and Beckett 2010).

Criminologists' reluctance towards integrating intersectionality wholeheartedly may also be explained by the criticisms that have been levelled towards the approach. Intersectionality has been described as nomenclature without being concretized (Knapp 2005), questioned for "naturalizing race, class, gender and identity as determinist forces that can fit and retain mainstream world views”, for being unreflective of the postcolonial dimensions of criminology (Henne and Troshynski 2013:14) and for not outlining a clear methodology (Nash 2008). Intersectionality is notoriously difficult to pinpoint in definitional terms and its fluidity and dynamism is regarded as both an opportunity and a dilemma in terms of establishing a common language (Collins 2015). Matters are compounded by the ongoing academic division of labour between qualitative and quantitative criminological methods. Quantitative approaches tend to sideline intersectional findings in favour of reporting on one variable and though statistical analyses can include more than one variable and report on the influence of various factors at the same time, scholarship tends to present findings on one variable in order to assuage any claims that the argument is 'too complex' or messy (Potter 2015). Whereas interaction effects report on the combination of two variables on a third, intersectionality acknowledges the effect of the individual variables as well as their combination altogether. 


\section{The Absence of Race}

The omission of race in British criminology is particularly striking, given the mutually constitutive relationship between criminalization and racialization. British criminology has always tended to shy away from direct discussions about race. Analyses of how race works (conjunction with criminalization, poverty, education) have been obscured by the move towards demonstrating or reiterating that racial inequality or discrimination continue to exist (Emirbayer and Desmond 2015). Although the continued significance of racial dynamics in the criminal justice system are important to highlight, little attention has been paid to explaining how racial dynamics are reconstructed and reinscribed though practices of criminal justice processing and social control.

Despite the plea made by intersectionality scholars to consider race, gender, class and other social identities concurrently and the need for their multiplicative effects to be recognised, commentaries on empirical research in the UK (across the social sciences), suggest that we are 'not quite there yet' (Ratna 2013). Discourses about race and otherness are typically interpreted through narratives of belonging and identity in the UK (Bosworth 2004) and when race is mentioned directly, it tends to be attenuated. In contrast to the US, the UK's role in the slave trade is rarely part of the national consciousness. Instead, it is presented as an externalised process, occurring beyond the physical borders of the UK, in British Caribbean and South American territories (Hondius 2009). As a result, current forms of racism and histories of colonialism, resistance and enslavement remain divorced from each other (Essed 2014). Concomitantly, the language of race is largely absent in the UK, with ethnicity the preferred term. Though laudable in its efforts to signal the subjective, symbolic and cultural aspects of group belonging and progressive in its attempt to denounce the reality of racial differences between humans, application of the term 'ethnicity' in British discourse also conceals explicit acknowledgement of the persisting reality of racialized structures which continue to employ ethnicity primarily as a colour coded phenomenon. As Gilroy (1993) has argued, ethnicity has simply become a euphemism for race and thus appropriated as such.

As mentioned above, although the concept of ethnicity acknowledges the subjective nature of identity, there are several problems in the way it is applied in criminology. For example, when criminologists categorise their sample populations as bounded ethnic groups, they rarely consider matters like the fluidity of ethnic identity and internal homogeneity within ethnic groups. At times, the ethnic categories used are too broad to be meaningful, with 'Asian', 'Mixed' 'White', 'Black' and 'Chinese and Other' being expected to reflect the diverse way in which people's identities are aligned. Occasionally the 
categories are expanded to allow specificity (e.g. Asian is divided into Asian British Indian, Asian British Pakistani or Asian British Bangladeshi), but broad categories remain when the issue of ensuring statistical significance is prioritised. Official statistics collated in this way also treat gender separately so there is little means to understand how gender and ethnicity intersect in criminal justice statistics, for example. There is a similar lack of information to understand how gender, generation and ethnicity intersect too, so for example, obtaining figures for the rates of black girls at various stages of the criminal justice system is not possible to ascertain using official Ministry of Justice figures.

More generally, criminological studies tend to only collect ethnic group data if the study is about racism or connections between ethnic group backgrounds and other variables related to crime and victimisation. Nationality is sometimes understood as a proxy for ethnic difference and visible markers of ethnic difference are taken for granted. Intra-ethnic homogeneity is rarely interrogated; ethnic group boundaries are represented as immutable; and citizenship, religion, nationality, culture and ethnicity are regularly elided (Fenton 2003). The symbolic or optional aspects of ethnicity (Waters 1990) are usually overlooked despite the obvious crossovers between crime, ethnic identity, racialization and otherness. Indeed, the decisions that participants in criminological studies make are often entangled with aspects of nationality, ethnicity and race and thus key to understanding penal regimes, sentencing practices, policing, border practices and processes of criminalization (Barker 2012; Bosworth 2004; Bosworth 2011; De Genova 2010).

Despite the inter-disciplinary potential for criminology to incorporate sociological perspectives, this has yet to be fully seized (Garner 2015). For example, concepts such as 'migrant', 'gang' and so on are racially coded and yet are uncritically utilised in criminology. Sociologists on the other hand explain that the term migrant and race are mutually constitutive; migration intimates disadvantaged status and the representation and positioning of 'the other' is coupled with non-white people from post-colonial societies (Song 2012; Erel 2016). The defence of space and power and access to citizenship is also criminalised and governed by racialized principles for some (Aas and Bosworth 2013; Chacon 2012; Sayad 2004), yet the racialized hierarchies that dictate the flow of human bodies across the globe and the racially defined and perceived 'threats' are hardly ever subject to analysis by criminologists. The fluidity and contradictions of narratives -- that frame asylum seekers as both needing help but also as dangerous criminals and potential terrorists -- are clearly racialized and arguably compel criminologists to consider the very pliability of racialized stereotypes when they become affixed to notions of criminality. 
British criminology however has largely overlooked these sociological analyses which illustrate the complexity of race/ethnicity and has instead worked to essentialize ethnicity and render it separate from gender, generation and class. The point therefore is that if ethnicity on its own is not dealt with adequately by criminological analysis, the expectation for intersectional approaches to be implemented in a nuanced way remains an unmet expectation in criminological scholarship in the UK. In short, we seemingly have a long way to go. Moreover, despite some notable exceptions (e.g. Webster 2008), criminologists have been all but silent about white ethnicities, with the work on white masculinities prioritising the intersection of working class identity amongst men. The white category continues to be the norm against which other group experiences are measured and outcomes compared (Solomos and Back 2000) or as Webster explains, 'white' appears as an empty signifier devoid of content except in its capacity to racialize other visible minorities. Race only features when the focus is on non-white participants (Guðjónsdóttir 2014; Frankenberg 1993) and underlying this lack of conceptual analysis is the notion that whiteness is something that is already defined or findable (Ware and Blaagaard 2011).

\section{British Asian Muslims: race and its new intersected modalities}

Looking to my own work on British Asians in the UK in a project which aimed to understand the consequences of counter-terrorist policing in the British context, I found that an intersectional framework was crucial to revealing the ways in which race, gender, post-coloniality, citizenship, generation and class featured in and framed the lives of British Asian men and their interactions with the police (Parmar 2011). British Asians have long represented a criminological puzzle for their offending patterns. Some groups like Bangladeshis - despite experiencing high levels of socio-economic deprivation, have very little engagement with the criminal justice system.

Projections indicating a rise in offending or arrests amongst Asian men because of demographic changes or the impact of second-generation cultural assimilation have not materialised. However, the increased focus on Asian men as potential terrorist suspects following the 7/7 London attacks led to the overpolicing and increased scrutiny towards this group (Parmar 2011, Fekete 2009). This disrupted the previous notion of Asian men as law abiding, subservient and predominantly victims within the criminal justice system that were based on historic and racialized narratives of non-criminality, subservience and effemininity, rooted in colonial constructions of Asian males (Sinha 1995).

My research focused on this very shift in the way in which Asian Muslim men are perceived and represented as the 'new folk devils' (Alexander 2001). Intersectionality allowed me to understand the way in which these new discourses subverted traditional notions of Asian masculinities and operated to frame 
cultural difference in a way that erased explicit mention of class disadvantage, disenfranchisement and racism. It also helped me to integrate questions of citizenship, belonging and nationality within my research frame whilst ensuring that I understood these issues and their refractions through masculinity, race, ethnicity, class and religion. I was able to document apparent contradictions such as the oppression shared by Black and Asian men (Ramamurthy 2013) whilst appreciating the cultural distance and complexity of Black and Asian experiences separately, as well as ways in which Asian hypermasculinities appropriated aspects of Black culture (and stereotypes of criminality) in order to garner power and gain attention from Asian women and white peers.

An intersectional approach which prioritised race also yielded better insight into the relationship between race, ethnicity and individual agency as in some cases of the stop and search encounter with the police that allowed my participants to question and reassert their sense of Asian group identity versus experiencing it as flatly constraining through racial profiling. For example, Asian Sikh men who were mistakenly profiled by the police as Asian Muslim were able to play with the misrecognition they experienced and this in their view delegitimised the stop and search encounter and exposed its underlying racist premise. At times humour and irony were used to resist the racializing consequences of being policed revealing the embeddedness of race and how it emerged and was dealt with in everyday settings (Harries 2014). Asians actively shaped their ethnic identities depending on the situation and ethnicity was engaged as a resource rather than solely imbued with struggle.

\section{Concluding Thoughts}

Race continues to be elusive in British criminological textbooks and syllabi, often seen as an adjunct or an afterthought rather than a primary research question. Despite the aspiration of scholars like Crenshaw that the notion of intersectionality would support, cajole and signify the importance of race alongside gender and other social cleavages, the result when we consider the state of British criminology is underwhelming. The need to understand and explore nuances in the relationship between race, gender and crime has always existed. However, as disproportionalities in criminal justice outcomes deepen (in the prison population for example), as intra-ethnic boundaries oscillate from being concretized to porous and the heterogeneity within ethnic groups is revealed, and the racialized reality of nationality and citizenship become more visible, the function of race, within the lived intersectional realities for all ethnic groups, is increasingly crucial for criminological debates. As Emirbayer and Mustafa note, there is a need 'to uncover the unconscious assumptions that produce blind spots in our thinking about race...' (2015:23). The inherently unstable nature of race and its new modalities, ensure that we must constantly appraise our approach to understanding it. As the focus on British Asian Muslims intensifies, for example, 
understanding the enmeshment of race and religion and its intricacies are vital; for example, research questions need to separate notions of religious observance from religious background, in order to mitigate against the reinforcement of superficial understandings of the relationship between religion and crime.

In the current context however, the consequences and effects of race have been recast, ambiguously and productively in commentaries on ethnicity, security, culture and religion (Gilroy 2012). Criminology's role is arguably to reveal, challenge and reinterpret such commentaries, to reveal their connections with racialization and criminalization. Thus criminological questions need to incorporate race more than ever before. Whether this is through the lens of intersectionality, or alongside it, the need for explicit discussion about race, racism and criminalization and how these issues operate together, is compelling. Furthermore, criminology is a space where the criminalization and securitization of some minority ethnic groups can also be potentially disrupted; criminology as well as a site for applying criminal or racialized identities to ethnic populations can be subverted to create an arena where the resistance to racialized identities can convene, become redefined or illuminated more accurately through empirical findings (Knepper 2008). At a time when the conceptual borders of ethnicity, religion, gender, nationality and class are not neatly distinguishable, the need for a nuanced and clear understanding and language of race and racism is all the more necessary in order for an intersectional approach to advance and transform British criminology.

\section{References}

Aas, Katja. and Bosworth, Mary. (eds.) .2013. The Borders of Punishment: Migration, Citizenship, and Social Exclusion. Oxford: Oxford University Press.

Alexander, Claire. 2001. The Asian Gang: Ethnicity, Identity, Masculinity. London, Berg.

Barker, Vanessa. 2012. 'Global Mobility and Penal Order: Criminalizing Migration, a view from Europe.' Sociology Compass 6 (2): 113-121.

Batia, Monish. 2015. 'Turning Asylum Seekers into 'Dangerous Criminals': Experiences of the Criminal Justice System of those Seeking Sanctuary’ International Journal for Crime, Justice and Social Democracy 4(3).

Berkeley, R. 2014. 'Finished Dreaming? The Post Race Delusion is Over- Back to Work' Huff Post Politics < http://www.huffingtonpost.co.uk/rob-berkeley/post-racial-delusion_b_4097387.html >

Bosworth, Mary and Flavin, Jeanne, (eds). 2007. Race, gender and punishment: From colonialism to the war on terror. New Brunswick, NJ: Rutgers University Press.

Bosworth, Mary. 2004. 'Theorizing Race and Imprisonment: Towards a New Penality' Critical Criminology 221.

Bosworth, Mary. 2011. 'Deporting Foreign National Prisoners in England and Wales' Citizenship Studies, 15, 583.

Bowling, Benjamin. 2013. 'Epilogue: The Borders of Punishment: Towards a Criminology of Mobility' in Mary Bosworth and Katja F. Aas (eds) Borders of Punishment: Migration, Citizenship and Social Exclusion. Oxford, Oxford University Press.

Chacon, Jennifer. 2013 'Overcriminalizing Immigration’, Journal of Crime, Law and Criminology, 102, 613. 
Collins, Patricia-Hill. 2000. Black Feminist Thought: Knowledge, consciousness and the politics of empowerment ( $2^{\text {nd }}$ ed.). New York: Routledge.

Collins, Patricia-Hill. 2015. 'Intersectionality’s Definitional Dilemmas', Annual Review of Sociology, 41: $1-20$.

Crenshaw, Kimberlé. 1991. 'Mapping the margins: intersectionality, identity politics, and violence against women of color.' Stanford Law Review 43, no. 6, 1241-1299.

De Genova, Nicholas. 2010. 'Antiterrorism, race, and the new frontier: American exceptionalism, imperial multiculturalism, and the global security state', Identities, vol. 17, no. 6, pp. 613-640.

Erel, Umut, Murji, Karim \& Nahaboo, Zaki. 2016. Understanding the contemporary race-migration nexus, Ethnic and Racial Studies, 39(8): 1339-1360

Essed, Philomena. 2014. 'A Brief ABC on Black Europe', in Invisible Visible Minority: Confronting Afrophobia and Advancing Equality for People of African Descent and Black Europeans in Europe. Brussels, European Network Against Racism.

Fekete, Liz. 2009. A Suitable Enemy: Racism, Migration and Islamophobia in Europe. London, Pluto Press.

Fenton, Steven. 2003. Ethnicity. London, Polity.

Frankenberg, Ruth. 1993. White women race matters: The social construction of whiteness, Minneapolis, MN: University of Minnesota Press.

Garner, Steve. 2015. Book Review Essay 'Crimmigration: When Criminology (Nearly) Met the Sociology of Race and Ethnicity’, Sociology of Race and Ethnicity, January (1): 198-203.

Gilroy, Paul. 1993. The Black Atlantic: Modernity and Double Consciousness. Cambridge: Harvard University Press.

Gilroy, Paul. 2012. "My Britain is fuck all' zombie multiculturalism and the race politics of citizenship," Identities: Global Studies in Culture and Power, 19:4, 380-397.

Giroux. Henry. A. 2009. Youth and the Myth of a Post-Racial Society Under Barack Obama, Policy Futures in Education, 7(5).

Goldberg, David, Theo. 2009. The Threat of Race: Reflections on Racial Neoliberalism. Malden, MA, Wiley-Blackwell.

Guðjónsdóttir, G. 2014. “"We blend in with the crowd but they don’t”: (In)visibility and Icelandic migrants in Norway', Nordic Journal of Migration Research, 4(4): pp176-183.

Harries, Bethan. 2014. 'We Need to Talk About Race', Sociology, 48(6): 1107-1122.

Henne, Kathryn and Troshnyski, Henne. 2013. 'Mapping the Margins of Intersectionality: Criminological Possibilities in a Transnational World', Theoretical Criminology 17(4):455-473.

Hondius, Dienke. 2009. 'Blacks in Early Modern Europe: New Research from the Netherlands'. Black Europe and the African Diaspora, 29-47.

Jones, Nikki. 2009. Between Good and Ghetto: African American girls and inner city violence. New Jersey, Rutgers University Press.

Knapp, G.A. (2005): 'Race, Class, Gender: Reclaiming Baggage in Fast Travelling Theories', European Journal of Women's Studies 12(3): 249-265.

Knepper, Paul. 2008. 'Rethinking the Racialisation of Crime: The Significance of African American "Firsts"'. Ethnic and Racial Studies, 31(3), 503-523.

Maher, Lisa. 1999. Sexed Work: Gender, Race and Resistance in a Brooklyn Drug Market. Oxford, Oxford University Press.

Nash, Jennifer. 2008. 'Rethinking Intersectionality’. Feminist Review, 89, 1-15.

Parmar, A. (2011) 'Stop and Search in London: Counter-Terrorist or Counter-Productive?’, Policing and Society, 21(4).

Phillips, Coretta and Bowling, Benjamin. 2003. 'Racism, ethnicity and criminology: developing minority perspectives'. British journal of criminology, 43 (2). pp. 269-290.

Phillips, Coretta and Bowling, Benjamin. 2012. Ethnicities, racism, crime and criminal justice, in Mike Maguire, Rod Morgan and Robert Reiner (eds.) The Oxford Handbook of Criminology. Oxford University Press, Oxford. 
Phillips, Coretta. 2012. The Multicultural Prison: Ethnicity, Masculinity and Social Relations among Prisoners. Oxford: Oxford University Press.

Phillips, Coretta and Webster, Colin. 2013. New Directions in Race, Ethnicity and Crime. Routledge, London.

Potter, Hillary. 2015. Intersectionality and Criminology: Disrupting and revolutionizing studies of crime. Abingdon, Routledge.

Ramamurthy, Anandi. 2013. Black Star: Britain’s Asian Youth Movements. London, Pluto.

Sayad, Abdelmalek. 2004. The Suffering of the Migrant. Cambridge. Polity Press.

Sinha, Mrinalini. 1995. Colonial Masculinity: The 'manly Englishman' and the 'Effeminate Bengali' in the Late Nineteenth Century. Manchester, Manchester University Press.

Solanke, Iyiola. 2009. Putting Race and Gender Together: A New Approach To Intersectionality, The Modern Law Review, 72(5): 723-749.

Solomos, John and Back, Les. 2000. 'Introduction: Theorising race and racism', in Theories of race and racism: a reader, eds Les Back \& John Solomos, Routledge, London, pp. 1-32.

Song, Miri. 2012. 'The Changing Configuration of Migration and Race' in Steven J. Gold, Stephanie J. Nawyn (eds), Routledge International Handbook of Migration Studies, London, Routledge.

Song, Miri. 2014. 'Challenging a Culture of Equivalence.’ British Journal of Sociology 65(1).

Song, Miri. 2016. 'Can There Be a Truly Systematic and Comprehensive Theory of Race?', Ethnic and Racial Studies, DOI: 10.1080/01419870.2016.1202425

Ware, Vron and Blaagaard, Bolette B. 2011. 'Workings of whiteness: interview with Vron Ware'. Social Identities, 17(1) pp. 153-161.

Waters, Mary. 1990. Ethnic Options: Choosing Identities in America. Berkeley, University of California Press.

Webster, Colin. 2008. 'Marginalized White Ethnicity, Race and Crime’, Theoretical Criminology, 12 (3): 293-312. 